\title{
A Study on the Influence of Team Members' Social Media Interaction Perception on Employee Creativity
}

\author{
Zhiqiang Huang, Saichao Chang, Jianhua Wu* \\ School of Business Administration, South China University of Technology, Guangzhou, China \\ Email: ^531349592@qq.com
}

How to cite this paper: Huang, Z.Q., Chang, S.C. and Wu, J.H. (2017) A Study on the Influence of Team Members' Social Media Interaction Perception on Employee Creativity. American Journal of Industrial and Business Management, 7, 1209-1228. https://doi.org/10.4236/ajibm.2017.711086

Received: October 10, 2017

Accepted: November 17, 2017

Published: November 20, 2017

Copyright (@) 2017 by authors and Scientific Research Publishing Inc. This work is licensed under the Creative Commons Attribution International License (CC BY 4.0).

http://creativecommons.org/licenses/by/4.0/

\begin{abstract}
Based on the questionnaire of 252 employees, this paper explores the relationship between social media interaction and employee creativity, which is influenced by the mediating effect of colleagues' trust and the moderating role of supporting organizational culture. The study found that: 1) Social media interaction among team members has a significant positive impact on employee creativity; 2) Social media interaction among team members indirectly influences employee creativity through trust; 3 ) The supporting organization culture regulates the relationship between social media interaction among team members and trust among them. That is to say, the higher level of the supporting organizational culture the employees perceive, the more obvious the influence of social media interaction among team members on the trust of colleagues is. This research not only enriches the theoretical research on the relationship between social media interaction and the internal stakeholders (employees) of the enterprise, but also has important guiding significance to the practice of organization management.
\end{abstract}

\section{Keywords}

Social Media Interaction, Employee Creativity, Colleague Trust, Supportive Organizational Culture

\section{Introduction}

With the rapid development of Internet technology, people in the enterprise use social media to communicate with each other more and more frequently, which enables the trans-time, cross-regional and all-weather information transmission and interaction realize. Social media interaction makes the dissemination of 
knowledge and information, the sharing of resources and the exchange of ideas become very instant and easy. The convenience of social media communication platform strengthens the contact and interaction among colleagues. In the aspect of emotion and work, the interaction among employees on the social platform has a great influence on the attitude and behavior of the colleagues in practical work. At present, the research on the relationship between social media and enterprises in the academic circle usually regards the external stakeholders such as enterprises or entrepreneurs and consumers as the research object. It explores how to use social media to establish good corporate or entrepreneurial image and brand image, cultivate customers' loyalty, attract consumer groups and so on. However, the study on the relationship between social media and internal stakeholders (employees) has begun to be paid attention by scholars.

Employee creativity is the cornerstone of organizational innovation and sustaining vitality (Amabile, 1988) [1]. The changing business environment requires the organization's internal staff to continually innovate (Christina et al., 2004) [2]. Previous studies have explored the impact on employee creativity from their personal factors such as emotion (George et al., 2007), active personality (Kim et al., 2002) [3], Intrinsic motivation (Zhang \& Bartol, 2010), and creativity self-efficacy. But scholars have found that the internal causes of employees can contribute to creativity. At the same time, the external cause of the employee's environment is also an important factor.

Many studies have examined their impact on employee creativity from the perspective of interpersonal interaction such as leader-member interaction, team-member interaction, and team communication. But most of the existing research focuses on the formal interactive processes and interactive content of organizations and ignores members' perception of the quality of the communication and interaction. At the same time, these studies do not examine the impact of interaction between team members through social media on employee creativity from the perspective of individual perceptions of communication. Whether social media interaction between team members can affect their creativity requires further study. In addition, the impact of organizational culture on staff creativity has been verified by many scholars. But it also needs empirical testing to incorporate organizational culture and team members' social media interaction and employee creativity into a model to examine their internal mechanisms.

Therefore, there are three main purposes of this study. Firstly, according to social exchange theory, we try to test the influence of social media interaction among team members on the creativity of employees. Secondly, we introduce the variable of colleague trust and test the intermediary effect between them. Finally, according to the theory of resource conservation, this paper explores the interactive effect of supporting organization culture and social media interaction by enhancing the influence of the intermediary variable of colleague trust on employees' creativity. 


\section{Literature Review and Research Hypothesis}

\subsection{Team Members' Social Media Interaction and Employee Creativity}

Due to the relatively short time of emerging media, scholars have done relatively little research on these emerging media, and their definitions of concepts are vague. Western scholar Antony Mayfield (2007) pointed out that social media is regarded as one of the online platform which integrates the functions of user participation, interaction, openness and transparency, conversation, connectivity and communication, etc. Then Andreas Kaplan and Michael Haenlein (2010) made a new definition of social media-based on the information content and interactive information model, it gives the user rights so that they can independently generate content and makes exchanging content. Whatever the concept, social media essentially emphasizes the exchange and interaction of information or emotional freely and voluntary voluntariness. Social media interaction refers to the dynamic process of the participants' (people or communication media's) communication, exchanging, acquiring and sharing for information or emotion through the online social media platform.

Based on the previous scholars' research, we choose the four dimensions-perceived usefulness, bi-directionality, responsiveness and mutual-aid as the focus of this study. Perceived usefulness refers to the value judgement on the acquired emotion or information from the colleague through the social media interaction; Bi-directionality means that both sides understand the meaning of each other's expression and willingness to interact with each other when interacting with colleagues through social media; Responsiveness refers to the perceived timeliness and relevance of colleagues' responses to his or her own questions or ideas when a person communicates with colleagues through social media; Mutuality means that a person is aware of the ability to share information, knowledge, resources and experience with your colleagues online and get some help or advice through social media interaction.

The interaction between team members through social media, as a mean of team communication, has played an important role in enhancing the instant exchange and sharing of information among members. Good team communication enables the sharing of internal information, intelligence, thought and emotion and the building of shared mental models to realize (Mohammed \& Dumville, 2001) [4], and it enhances team innovation through the integration of professional knowledge, ideas and resources (Patrashkova-Volzdoska et al., 2003) [5]. Social media interaction enhances the convenience and immediacy of communication, which not only makes the content of the information richer but also makes the object of communication more free. On the other hand, social media interaction breaks the time and place constraints, which enables team members to achieve non-workplace and non-working time communication through social media. This expansion of the working environment in the communication is conducive to enhancing the mutual understanding and trust between members 
and the overall level of collaboration and vitality. But it is not to say that the more social media interaction there is, the more favorable it will be to individual creativity. Excessive communication may cause information flooding, increase the cost of information processing time and conceal possible innovative ideas (Smith et al., 1994) [6]. Similarly, lack of communication hinders team creativity by not being able to fully and effectively integrate the team's expertise and information resources (Denison, D et al., 1996) [7]. In the past, few scholars have explored the impact of communication on their creativity from the perception of the quality of interaction among members. Hurt et al. (1977) [8] argue that employee satisfaction and preference for communication quality is also an important factor influencing employee creativity.

According to the theory of social exchange, the relationships between individual and team colleagues, such as mutual trust, information sharing, mutual assistance and mutual benefit, can positively affect individual attitudes and behaviors (Seers A, 1989) [9]. On the one hand, individuals who interact with team members can get information, resources, knowledge support. In the process, the stronger the willingness of individuals to share knowledge or communicate with others is, the more likely they will acquire the new knowledge needed for innovation (Woodman, 1993) [10]. On the other hand, a good interaction between team members can be used to promote mutual trust and even offer psychological support, such as encouragement, affirmation, self-efficacy, security, etc., which is conducive to relieve psychological stress caused by breaking the convention and innovation failure in the process of innovation. The Scott et al. (1994) [11] also found that the quality of relationships between individuals and team members have positive effects on individual creativity. Therefore, this paper makes the following assumptions:

H1: Social media interaction perception has a positive impact on employee creativity.

\subsection{The Intermediary Role of Employee Trust}

Trust is one's unguarded state of mind based on the positive judgement of the trustee's motivation and behavior (Rousseau et al., 1998) [12]. At present, most of the researches recognizes that trust can be divided into two dimensions: cognitive trust and emotional trust. Some scholars have found that there is a clear correlation between interaction and interpersonal trust. For example, the study of McAllister (1995) found that the interaction between team members will have a significant impact on the establishment of mutual trust. When communication increases, the positive beliefs will be enhanced. Meanwhile, the perceived trust between employees and the likelihood of cooperation will also increase (Anderson et al., 2004) [13].

Positive interaction has a positive impact on trust because one party has a good, positive perception of the other in the process of interaction. First, good perceived usefulness not only allows the recipients to obtain valuable informa- 
tion or knowledge from the interaction to help them do their work better, but also the psychological emotional support from the other side also allows individuals to perceive the goodwill of colleagues. When feeling the help from others, the individuals will be more inclined to trust others. Second, when colleagues interact through social media, positive bi-directionality perception will allow members to perceive that colleagues are willing to interact with themselves. Even-more, when their problems are well understood and communicated, the individual's acceptance and the sense of trust will affect their trust in the treatment of colleagues. Third, the positive response will make people feel that colleagues respect or attach importance to them and are willing to communicate with them, which reduce the sense of distance between members. At the same time, the effective and timely response can help them to answer doubts and then enhance the trust. Fourth, the mutual perception in the process of interaction not only makes both the two sides of communication get their place, but also increase the opportunities to communicate and even enhance mutual trust through the exploration of problems. A positive judgment on colleagues can be formed through these positive perceptions, such as accepting each other's sincerity, goodness, communication skills, knowledge reserve capacity, ability to work and so on, and an emotional dependency relationship will be gradually formed.

A large number of studies have found that trust can positively influence individuals' attitudes and behaviors (Dirks, 2002; Dyer, 2003) [14]. The impact of trust on employee creativity is mainly through three ways. First, good interpersonal trust between team members can promote better communication among members, the sharing and collaborating of knowledge information, and meanwhile, the gathering of different knowledge and collision of ideas can inspire good ideas and programs. Second, good interpersonal trust can reduce the sense of insecurity of members. When members feel the trust between the members of the team, they are more willing to accept the views, express ideas, share their own resources and even bear the risk that knowledge sharing may bring. Conservation of resource theory argues that when individuals feel that their resources may be at risk for harm, they will take measures to protect or hide the value of resources. So he is less willing to share his knowledge, information or ideas with others (Hobfoll, 2002) [15], which is not conducive to the emergence of innovation. To sum up, this paper makes the following assumptions:

H2: Trust relationship has mediating effect between the social media interaction perception of colleagues and employee creativity.

\subsection{The Moderating Effect of Supporting Organizations' Cultural Perception}

Organizational culture is the way in which the common values and the way of thinking are consistent with the common values and things that are treated in the course of a long period of business. It is also a guide to the organization of 
activities. Wallach (1983) [16] divides organizational culture into bureaucratic culture, innovation culture, supportive culture, and organizational culture based on the interaction between members of the organization. And pointed out that the bureaucratic culture is characterized by the organizational hierarchy and the division of powers and responsibilities is very clear, clear, most of the nature of the work of standardization or immobilization; Innovative culture is characterized by creativity and risk, emphasis on members of the challenges and innovation, respect for uniqueness, to allow members to risk culture; Supportive culture of the organization of its environment more freedom and harmony, employees can feel the same home atmosphere, the organization has a higher degree of trust and support, pay attention to team spirit and interpersonal relationships. Different organizational cultures have different degrees of influence on the psychological perception and behavior of the members of the organization in different ways (Taylor S et al., 2008) [17].

Although the interaction of employees through social media interaction to usability, two-way, responsiveness and mutual help is beneficial to the improvement of team members' mutual trust, the social media interaction between employees depends on the perception of organizational culture, When employees perceive a high level of supportive culture, on the one hand, they will think that the use of emerging social media communication can be accepted and trusted by the organization, and can actively use social tools to improve the interpersonal relationship between members of the work team, and believe that such behavior will be recognized by the organization; on the other hand, when the organization's cultural atmosphere emphasizes harmonious trust and family-like warmth, employees tend to think that the relationship between members of the organization is harmonious and trustworthy (Wallach, 1983; Quinn R, 1991) [18]. Because of the shared values, social interaction between colleagues reduces communication anxiety, which in turn enhances employee trust. However, when employees perceive the supportive culture of the organization is not obvious, they are not sure that the organization's attitude towards social media interaction, the pressure of their own value resources threatens to stimulate the job safety of employees (Hobfoll, 2002) There may be a risk of damage to the value of the resource, which will take the appropriate action (Ren \& Zhang, 2015) [19], so that employees may respond accordingly by reducing the active interaction or symbolic response. Thus, the impact of social media interaction on the trust of team members is relatively reduced. In addition, when employees perceive the weak cultural atmosphere, will think that the cultural atmosphere of trust within the organization is also not prominent, the social media interaction between members of the organization on the degree of trust will also be relatively weakened. To sum up, this paper makes the following assumptions:

H3: support organization culture perception has a positive role in the relationship between social media interaction perception and trust, that is, when the perceived organizational culture atmosphere is higher, the impact of social me- 
dia interaction perception on employee trust is stronger.

In summary, the theoretical model of this paper is shown in Figure 1.

\section{Research Methods}

\subsection{Data Collection}

In this study, the research data were collected by questionnaire.

This research questionnaire is collected in two ways, the first is to go to the research enterprise to issue the questionnaire and the recovery; the second is to ask the person in charge of the enterprise to help organize the employees to fill in it on the internet, so this study uses the questionnaire software to collect some Data, but the link is not shared to the public, but targeted to send links to the employees of the business being investigated.

The survey covers 18 companies in 5 provinces but mainly focuses on the Pearl River Delta and the Yangtze River Delta and other places. Questionnaires are targeted at working people who use social media tools such as micro switches, $\mathrm{QQ}$, microblogging, e-mail and so on. In the selection of target enterprises, because of taking the frequency of social media used at work, application and other factors into account, our main choice is the companies of Internet, computer, media and management consulting and some research institutions. A total of 350 questionnaires were distributed in this survey. After validating the incomplete and invalid questionnaires, the number of valid questionnaires was 252 and the effective rate was $72 \%$.

The respondents surveyed were roughly balanced in sex ratio, with men (55.6\%) and women (44.4\%). The age of the respondents was between 26 - 35 years old $(70.2 \%)$, belonging to the young and middle-aged groups. The survey was mainly based on undergraduate and master's degree education (76.6\%). In addition, the length of service is mainly concentrated between 3 and 9 years (65.9\%).

\subsection{Variable Measurement}

By reading a lot of literature, we can see that the researchers have defined the variables in this paper from different perspectives. Based on this background, according to the research situation of this paper, the author makes a clear definition of the variables studied in this paper, as shown in Table 1 . The scale of the selected variables in this study is derived from the mature scale of the existing

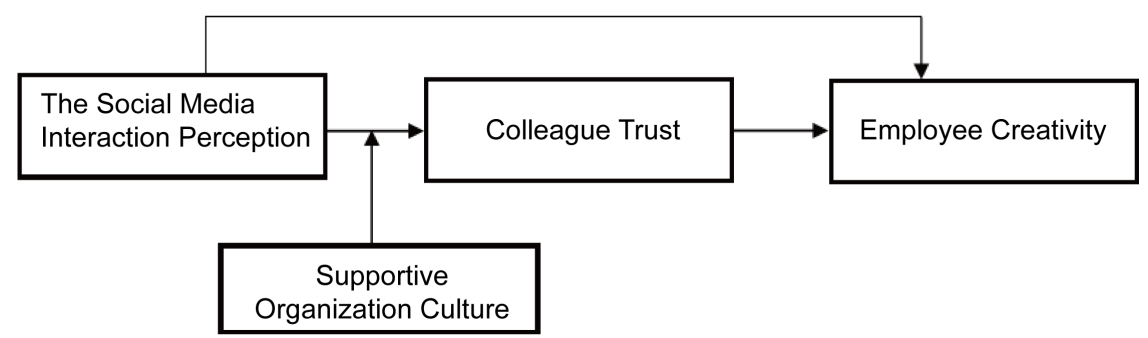

Figure 1. The relationship model of team members' social media interaction perception, colleague trust, supportive organizational culture and employee creativity. 
Table 1. Definition of variable.

\begin{tabular}{|c|c|}
\hline Variable & Definition \\
\hline Social Media & $\begin{array}{l}\text { After combing social media literature, the social media explored in this study is defined as a network, } \\
\text { media tools or platforms that is similar to we-chat, QQ, micro-blogs, etc. that enable participants to inte- } \\
\text { ract or share information, ideas, resources, and emotions. }\end{array}$ \\
\hline Interaction & $\begin{array}{l}\text { Through the relevant literature review, we can see that the current scholars divide Interaction into several } \\
\text { dimensions in the following ways: one is based on interactive attribute dimension division, and the other } \\
\text { is based on interactive content dimension division, the third is based on the interactive direction of the } \\
\text { dimension division. }\end{array}$ \\
\hline Social Media Interaction Perception & $\begin{array}{l}\text { This study explores the interpersonal interaction between colleagues based on the perspective of } \\
\text { perceptual interaction, and thus the interaction of social media is appraised by measuring the } \\
\text { employees' perception of each interactive factor [20]. }\end{array}$ \\
\hline Trust & $\begin{array}{l}\text { By combing the literature of trust and the need for this study, this paper explores interpersonal trust } \\
\text { relationships between people in the organization and regards trust as a personal mental state or attitude. }\end{array}$ \\
\hline Employee Creativity & $\begin{array}{l}\text { The definition of creativity, although different opinions, but through a large number of representative } \\
\text { scholars of the creative process of the definition of finishing, can be divided into the following four } \\
\text { points: personality theory, process theory, results theory and ability theory. On this basis, this article } \\
\text { defines employee creativity as the ability of individuals to generate new ideas or new products. }\end{array}$ \\
\hline Supporting organization culture & $\begin{array}{l}\text { Support-oriented culture emphasizes participation, collaboration, people-centered, social, mutual trust, } \\
\text { group cohesion and personal growth, often in an oral, informal way of communication; communication } \\
\text { and making decisions to encourage employees to express their views on work and others. Pay attention to } \\
\text { each employee's recognition of the organization. } \\
\text { Emphasizing the collection of new information in the external environment, creativity, prediction, testing } \\
\text { and openness to change, often take informal, in all directions to communicate, top-down control is } \\
\text { neither possible nor necessary, In the management of staff expectations of the work and organizational } \\
\text { objectives of the recognition and participation [21]. }\end{array}$ \\
\hline
\end{tabular}

studies. The scores used in this study are given by Likert 5 points, in which "1" means "totally disagree", "5" totally agree". To ensure the accuracy of the translation of the scale, the scale used in this study made situational adaptability under the guidance of two management professor on the basis of the amendments of a $\mathrm{PhD}$ in psychology and a master's English translation. The scale is as follows:

Measurement of Social Media Interactive Perception. This study explores the interpersonal interaction between colleagues based on the perspective of perceptual interaction, and thus the interaction of social media is appraised by measuring the employees' perception of each interactive factor. Among them, the measurements of the dimensions are: perceived usability (Gefen et al., 2003) [22], responsiveness (Ruyter et al., 2000; Yin, 2002) [23], bidirectionality (burgoon et al., 2000; Yin, 2002). The measurement of mutual aid uses the scale compiled by Jiageng Tang (2006) [20] according to the domestic situation, adapts the relevant items and then determines the dimensions and related items of the interactive part of the social media. There are four items in each dimension, 16 items in total. By data analysis, the Cronbach's $\alpha$ of the scale was 0.899 .

The measurement of "Trust". The confidence scale developed by McAllister (1995) was used to measure the trust relationship between colleagues. The sec- 
tion of the scale used a total of 10 items, of which there are five items on the emotional trust and five items on the cognitive trust. The scale of Cronbach's $a$ was 0.835 .

Measurement of employee creativity. The scale developed by Farmer et al. (2003) [24] was used, four items included. For example, "he can come up with innovative ideas or methods to solve problems at work." The scale of Cronbach's a was 0.801 .

Supportive organizational culture perception. The scale developed by Quinn et al. (1991) and Wallach (1983) was applied. A total of six items were included, such as "working in the company can give people a sense of security", "the company can give employees a considerable autonomy and freedom" and so on. The scale of the Cronbach's a was 0.813 .

Control variable. This study selected gender, age, degree of education and years of working as control variables.

\subsection{Principles of Questionnaire Design}

First of all, the scales used in this paper are all mature scales published in the first-class journals, and to disrupt the order of the title in the design of the questionnaire, as much as possible to ensure the subjects fill in the questionnaire sincerely; Using the reverse design to prevent the subject to fill out, but also through this way to filter out invalid questionnaires;

Secondly, this paper carries out pre-test analysis (including project analysis, reliability analysis and validity analysis) of the questionnaire through the relevant data collected to test the scientificity of the relevant scale of this study.

Finally, the three scales used in this study were pre-tested to form the final formal questionnaire.

\subsection{Verify the Hypotheses}

In this paper, the author use three types of intermediary effect test method proposed by Mackinnon (2002) to verify t intermediary effect of the colleagues' trust in the model:

(1) casual steps approach

(2) difference in coefficients

(3) products of coefficients

As these test methods all have flaws in some aspects, therefore, we use MPLUS6.0 do the mediating effect Bootstrap test methods.

\section{Research Result}

\subsection{Confirmatory Factor Analysis and Common Method Variance Test}

In order to test the common method variance of the data in this study, we use the confirmatory factor analysis to test the discriminant validity of the predicted variables in different models, as shown in Table 2. The comparative indexes 
Table 2. The result of confirmatory factor analysis $(\mathrm{N}=252)$.

\begin{tabular}{ccccccccc}
\hline Model & $\chi^{2}$ & $\mathrm{df}$ & $\chi^{2} / \mathrm{df}$ & RMSEA & IFI & TLI & CFI & AIC \\
\hline 4-factors model & 747.564 & 562 & 1.330 & 0.036 & 0.950 & 0.943 & 0.949 & 955.564 \\
3-factors model A & 1161.091 & 583 & 1.992 & 0.063 & 0.844 & 0.829 & 0.842 & 1327.091 \\
3-factors model B & 1243.390 & 588 & 2.115 & 0.067 & 0.822 & 0.807 & 0.820 & 1399.390 \\
3-factors model C & 1324,124 & 589 & 2.195 & 0.069 & 0.809 & 0.794 & 0.807 & 1446.982 \\
2-factors model & 1456,522 & 593 & 2.456 & 0.076 & 0.766 & 0.749 & 0.763 & 1602.522 \\
1-factors model & 1688.710 & 594 & 2.843 & 0.086 & 0.703 & 0.682 & 0.700 & 1832.710 \\
\hline
\end{tabular}

Annotation: In model A we combine supportive culture and colleague trust; In model B we combine colleague trust and employee creativity; In model C we combine social media interaction and employee creativity; We combine social media interaction and supportive culture as one factor and combine colleague trust and employee creativity as the other factor in 2-factors model.

adopted in this study mainly include 6 indicators such as $\chi^{2}, \mathrm{df}, \chi^{2} / \mathrm{df}, \mathrm{RMSEA}$, IFI, TLI, CFI and AIC. $\left(\mathrm{X}^{2} / \mathrm{df}=1.330\right.$, less than 3 ; RMSEA $=0.036$, less than 0.05 ; IFI, TLI, CFI three indicators are greater than 0.9). The results show that the predictive variables have good discriminant validity by the comparison of the benchmark model and the alternative model.

\subsection{Descriptive Statistics}

The mean and standard deviation of each variable and the correlation coefficients between the variables are shown in Table 3. The results show that there is a significant positive correlation between social interaction between colleagues and colleagues' trust and employee creativity, and that there is also a significant positive correlation between colleague trust and employee creativity.

\subsection{Hypothesis Text}

(1) As can be seen from Table 4:

The social media interaction between team members has a significantly positive influence on employee creativity $(\beta=0.569, \mathrm{p}<0.01)$. As shown in Model 5 , the better the perception of social media interaction among members is, the stronger the effect on the individual's creativity is. So, the hypothesis 1 has been supported.

(2) As shown in Model 2, the interaction of social media between team members has a significant positive impact on the trust of colleagues $(\beta=0.641, \mathrm{p}<$ 0.01). The results of Model 6 show that colleagues trust has a significant positive effect on employee creativity $(B=0.559, \mathrm{p}<0.01)$. This conclusion provides further support for Hypothesis 2. In addition, in order to further examine the rationality and validity of the mediating effect results, the mediation effect test was conducted according to the bootstrap method proposed by Hayes (2013) [25] and the mediation effect analysis procedure proposed by Zhao et al. (2010) [26], we choose 2000 as sample size. Under $95 \%$ confidence interval, the results of the intermediate test did not contain $0($ LLCT $=0.1081$, ULCI $=0.2934)$, which indicates that the mediating effect of colleague trust was significant, and 
Table 3. The means, standard deviation and the correlation coefficients.

\begin{tabular}{|c|c|c|c|c|c|c|c|c|c|c|}
\hline Variable & $\mathbf{M}$ & $\mathrm{SD}$ & 1 & 2 & 3 & 4 & 5 & 6 & 7 & 8 \\
\hline 1 Gender & 1.44 & 0.498 & 1 & & & & & & & \\
\hline 2 Age & 2.62 & 1.005 & $-178^{\star *}$ & 1 & & & & & & \\
\hline 3 Education & 1.94 & 0.641 & 0.003 & $-0.181^{\star *}$ & 1 & & & & & \\
\hline 4 Years of Working & 2.05 & 0.857 & -0.119 & $0.703^{\star *}$ & $-0.198^{\star *}$ & 1 & & & & \\
\hline 5 Social Media Interaction & 3.48 & 0.526 & 0.085 & $-0.152^{*}$ & 0.061 & -0.08 & 1 & & & \\
\hline 6 Supportive Culture & 3.45 & 0.535 & 0.044 & -0.117 & -0.003 & -0.096 & $0.697^{\star \star}$ & 1 & & \\
\hline 7 Colleague Trust & 3.50 & 0.451 & 0.053 & 0.008 & 0.023 & 0.020 & $0.626^{\star *}$ & $0.455^{\star *}$ & 1 & \\
\hline 8 Employee Creativity & 3.47 & 0.49 & 0.078 & -0.105 & $0.150^{*}$ & -0.043 & $0.561^{\star *}$ & $0.371^{\star \star}$ & $0.562^{\star *}$ & 1 \\
\hline
\end{tabular}

Annotation: $\mathrm{n}=252 ;{ }^{*}$ denote $\mathrm{p}<0.05 ;{ }^{* *}$ denote $\mathrm{p}<0.01$, the same below.

Table 4. The result of multiple regression.

\begin{tabular}{|c|c|c|c|c|c|c|}
\hline \multirow{2}{*}{ Variable } & \multicolumn{3}{|c|}{ Colleague Trust } & \multicolumn{3}{|c|}{ Employee Creativity } \\
\hline & Model 1 & Model 2 & Model 3 & Model 4 & Model 5 & Model 6 \\
\hline Constant & $3.356^{* *}$ & $1.437^{\star *}$ & $1.127^{\star *}$ & $3.226^{* *}$ & $1.371^{\star *}$ & $1.181^{* *}$ \\
\hline Gender & 0.052 & 0.018 & 0.016 & 0.018 & -0.017 & -0.014 \\
\hline Age & 0.001 & 0.113 & 0.100 & -0.047 & 0.053 & -0.047 \\
\hline Education & 0.021 & 0.004 & 0.009 & 0.120 & 0.097 & 0.103 \\
\hline Years of Working & 0.017 & -0.005 & 0.016 & 0.092 & 0.059 & 0.074 \\
\hline Social Media Interaction & & $0.641^{\star *}$ & $0.642^{* *}$ & & $0.569^{* *}$ & \\
\hline Colleague Trust & & & & & & $0.559^{* *}$ \\
\hline Supportive Culture & & & 0.084 & & & \\
\hline $\begin{array}{l}\text { Social Media Interaction } \times \\
\text { Supportive Culture }\end{array}$ & & & $0.209^{\star *}$ & & & \\
\hline $\mathbf{F}$ & 0.271 & $33.272^{\star *}$ & $27.746^{\star *}$ & 1.056 & $24.338^{\star *}$ & $24.021^{\star *}$ \\
\hline $\mathbf{R}^{2}$ & 0.004 & 0.403 & 0.443 & 0.017 & 0.331 & 0.328 \\
\hline$\Delta \mathbf{R}^{2}$ & & $0.391^{\star *}$ & $0.427^{\star *}$ & & $0.317^{\star *}$ & $0.314^{* *}$ \\
\hline
\end{tabular}

the mediating effect size was 0.2028 . In addition, the influence of self-variable social media interaction perception on employee creativity is also significant $(\mathrm{LLCT}=0.2036, \mathrm{ULCI}=0.4376, \mathrm{p}<0.01)$. As a result, colleague trust plays a mediating role between social media interaction perception and employee creativity. So, hypothesis 2 has been supported.

(3) In order to examine the regulatory role of the supportive organization culture between social media interaction and trust, this study centralize the variables and get the interaction items of the social media interaction and supportive culture perception at first. As the model 3 shows, the social media interaction perception $(\beta=0.641, p<0.01)$ had a significant effect on the trust of colleagues, and the impact of the social media interaction perception and suppor- 
tive culture perception $(\beta=0.209, \mathrm{p}<0.001)$ on the trust of colleagues is also significant. In order to further test the regulation effect, this study also used Mplus6.0 to calibrate the percentage of the Bootstrap test, selected the sample size of 5000 and the confidence interval whose coefficient is $95 \%$. The results show that the first half of the model, that is, the impact of social media interaction perception on colleague trust, is significantly regulated by the perception of supportive organizational culture $(\mathrm{LLCT}=0.047$, ULCI $=0.227$ ).

In order to explain the regulation effect more intuitively, this study uses the Simple slope test to analyze. As shown in Figure 2, under the high supportive organizational culture perception, the social media interaction among the team members has stronger effect on the trust of the colleagues. Thus, Hypothesis 3 is supported.

\section{Discussion and Conclusion}

\subsection{Research Conclusions}

Based on the theory of social exchange and conservation of resources, this study explores the impact of positive social media interaction perception on employee creativity. At the same time, this paper also examines the intermediary effect of the trust among colleagues. Research shows that social media interaction among colleagues is also an important antecedent of employee creativity. This conclusion verifies that the social media interaction perception can enhance the creativity of the employees in the local context. Second, trust in colleagues plays a mediating role between social media interaction perceptions and employee creativity. This conclusion shows that employees' perceptions of the quality of social media interaction between co-workers can affect the trust relationship between colleagues and that the trust among team members can significantly affect employees' creativity. This provides a new way of explaining how social media interaction affects employees' creativity. Interactive perceptions of social media have a significant impact on the trust of colleagues. But when the organizational

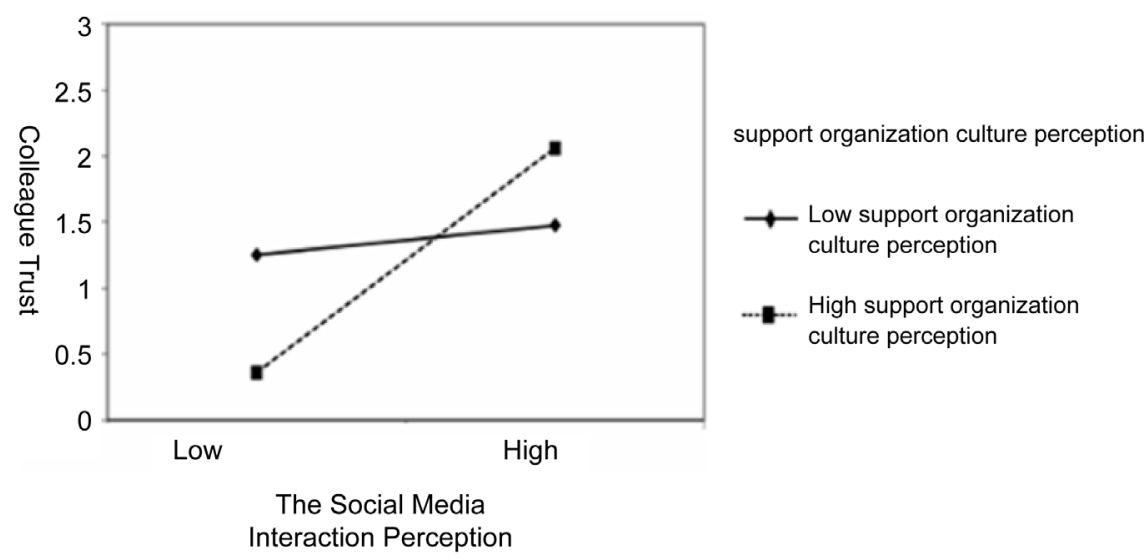

Figure 2. The Diagram on the regulatory effect of supportive organizational culture perception on the relationship between social media interaction perception and colleague trust. 
culture that employees perceive is supportive, employees have an enhanced role in the relationship between social media interaction perceptions and trust. This conclusion shows that the relationship between social media interaction perception and employee creativity will show the differences in different organizational environments.

\subsection{Theoretical Contribution}

The theoretical significance of this study mainly includes three aspects. First, the antecedents of employee creativity have been validated by many studies (Amabile, 2004) [27], but the research on the impact of employee creativity is relatively scarce from the perspective of communication and interaction between colleagues. At the same time, the conclusions of these studies are inconsistent. In this paper, social media interaction is identified as a predictor variable to explore the influencing mechanism of employees' perception of the communication quality on the attitude and behavior of employees. It also validates that social media interaction among colleagues can positively influence employee creativity in the context of social media usage. Therefore, this study expands and enriches the understanding of the factors influencing the creativity of employees in the local context.

Secondly, this study, based on the theory of social exchange and conservation of resources, puts forward that the trust of colleagues is the intermediary variable of the influence of the social media interaction perception on employee creativity. In the past, most studies have suggested that knowledge sharing is an intermediary mechanism of the influence of team members' communication on employee creativity. But we think that these explanations are not very good for understanding the relationship between team members' communication and employee creativity. Because most of these studies, according to the theory of social exchange, are sharing behavior based on communication relation between members within a team and between members and managers. However, in addition to the simple exchange between members and supervisors, there is also an emotional trust relationship (Barnett M, 2007) [28]. The theory of resource conservation holds that employees may take the risks of their behaviors into account when making decisions about knowledge sharing. This risk is reduced only when team members form a close relationship of trust.

Previous studies have overlooked the fact that one of the reasons behind knowledge sharing is employees' trust. Therefore, this study defines trust from two dimensions which includes cognitive trust and emotional trust. This paper explores the mediating effect between social media interaction perception and employee creativity. The findings show that the team members with high social media interactions can perceive higher trust (cognitive trust and emotional trust). So they are willing to be more actively involved in cooperation, get to access information resources and more positive mental hints. In addition, the acquisition cost and psychological cost of knowledge information resources are 
reduced, which ultimately contributed to the promotion of staff creativity. This study has a certain theoretical significance for further revealing the relationship between social media interaction and staff creativity.

Finally, this study also explores the moderating effect of organizational culture on the relationship between social media interaction and trust. It explains why the same social media interaction can have a different impact on employees' behaviors. And using data to validate the supportive organizational culture can enhance the intermediary role of peer trust in social media interaction perception and employee creativity model.

\subsection{Practical Significance}

How to improve the creativity of employees and the performance, adaptability and competitiveness of enterprises has received many concerns by the organizations and managers (Nonaka, 1991; Zhou, 2003) [29]. Companies are taking a number of steps to try to boost employee creativity (Hirst et al., 2015) [30], but the effect is not ideal. On the one hand, enterprises actively encourage team members to communicate and collaborate with each other, and trust and help each other. They share knowledge, resources and knowledge in order to promote innovation. On the other hand, the organization is worried that too much communication interaction increases the time cost and reduces the efficiency of decision-making. Even this accumulation of information can result in the drowning of value information. In the end, this creates an ineffective interaction. Therefore, under the dilemma, most organizations will seize the initiative in their own hands, and limit the communication medium between team members as far as possible. However, through empirical research, social media interaction among team members can also promote the improvement of staff creativity. Therefore, in the practice of management, managers should pay attention to the quality of social media interaction among team members. At the same time, they should actively encourage and guide members to communicate and interact properly. Managers should abandon the idea of absolute control and give employees trust and care to weaken the speculative notion of members on the ineffective interaction, combined with appropriate assessment mechanisms.

In addition, the article found that social media interaction among team members can significantly enhance the trust between colleagues. For team members, they should take full advantage of the opportunity to interact with other members of the team through social media. They should actively share the valuable information and knowledge and communicate with each other. In addition, they should help each other. This contributes to the establishment of mutual cognitive trust and emotional trust. Mutual trust among members is useful for building a good interpersonal network and obtaining innovative resources (Perry-smith et al., 2003) [31]. At the same time, it also helps to enhance their creativity. 


\subsection{Research Limitations and Future Research Directions}

Firstly, the measurement of all variables in this study was measured at the same time point. Technically speaking, there is the deviation of data common method in this paper. Confirmatory factor analysis verifies that there is a good distinction between the variables of validity, but it is still not possible to pinpoint the intrinsic relationship between social media interaction and employee trust and employee creativity. In addition, the trust between members and the formation of staff creativity requires a course to go through, in which there may be time lag. Therefore, future research can further examine the causal relationship between variables through longitudinal design.

Secondly, this study chooses the mediating role of colleagues' trust between social media interaction and staff creativity. But the discussion of intermediary mechanism is far from enough. The future research can be examined from the aspects of employee self-efficacy and team identification. This will reveal more fully the unknown relationship between the two.

\section{References}

[1] Amabile, T.M. (1988) A Model of Creativity and Innovation in Organizations. Research in Organizational Behavior, 10, 123-167.

[2] Shalle, C.E. and Gilson, L.L. (2004) What Leaders Need to Know: A Review of Social and Contextual Factors That Can Foster or Hinder Creativity. The Leadership Quarterly, 15, 33-53. https://doi.org/10.1016/j.leaqua.2003.12.004

[3] Bock, G.W. and Kim, Y.G. (2002) Breaking the Myths of Rewards: An Exploratory Study of Attitudes about Knowledge Sharing. Information Resources Management Journal, 15, 14-23. https://doi.org/10.4018/irmj.2002040102

[4] Mohammed, S. and Dumville, B.C. (2001) Team Mental Models in a Team Knowledge Framework: Expanding Theory and Measurement across Disciplinary Boundaries. Journal of Organizational Behavior, 22, 89-106. https://doi.org/10.1002/job.86

[5] Patrashkova-Volzdoska, R.R., Mc Comb, S.A., Green, S.G. and Compton, W.D. (2003) Examining a Curvilinear Relationship between Communication Frequency and Team Performance in Cross-Functional Project Teams. IEEE Transactions on Engineering Management, 50, 262-269. https://doi.org/10.1109/TEM.2003.817298

[6] Smith, K.G., Smith, K.A., Olian J.D., Sims Jr., H.P., O’Bannon, D.P. and Scully, J.A. (1994) Top Management Team Demography and Process: The Role of Social Integration and Communication. Administrative Science Quarterly, 39, 412-438. https://doi.org/10.2307/2393297

[7] Denison, D.R., Hart, S.L. and Kahn, J.A. (1996) From Chimneys to Cross-Functional Teams: Developing and Validating a Diagnostic Model. Academy of Management Journal, 39, 1005-1023. https://doi.org/10.2307/256721

[8] Hurt, H.T. and Teigen, C.W. (1977) The Development of a Measure of Perceived Organizational Innovativeness. Sage, Newcastle upon Tyne, 377-385.

[9] Seers, A. (1989) Team-Member Exchange Quality: A New Construct for Role-Making Research. Organizational Behavior and Human Decision Processes, 43, 118-135. https://doi.org/10.1016/0749-5978(89)90060-5

[10] Woodman, R.W., Sawyer, J.E. and Griffin, R.W. (1993) Toward a Theory of Orga- 
nizational Creativity. Academy of Management Review, 18, 293-321.

[11] Scott, S.G. and Bruce, R.A. (1994) Determinants of Innovative Behavior: A Path Model of Individual Innovation in the Workplace. Academy of Management Journal, 37, 580-607. https://doi.org/10.2307/256701

[12] Rousseau, D., Sitkin, S., Burt, R., et al. (1998) Not So Different after All: A Cross Discipline View of Trust. Academy of Management Review, 23, 393-404. https://doi.org/10.5465/AMR.1998.926617

[13] Anderson, L.R., Jennifer, M.M. and Jeffrey, M. (2004) Social Capital and Contributions in a Public Goods Experiment. American Economic Review Papers and Proceedings, 94, 373-376. https://doi.org/10.1257/0002828041302082

[14] Dirks, K.T. and Ferrin, D.L. (2002) Trust in Leadership: Meta-Analytic Findings and Implications for Research and Practice. Journal of Applied Psychology, 87, 611-628. https://doi.org/10.1037/0021-9010.87.4.611

[15] Hobfoll, S.E. (2002) Social and Psychological Resources and Adaptation. Review of General Psychology, 6, 307-324. https://doi.org/10.1037/1089-2680.6.4.307

[16] Wallac, E. (1983) Individuals and Organizations: The Cultural Match. Training and Development Journal, 37, 29-36.

[17] Taylor, S., Levy, O., Boyacigiller, N.A., et al. (2008) Employee Commitment in MNCs: Impacts of Organizational Culture, HRM and Top Management Orientations. The International Journal of Human Resource Management, 19, 501-527. https://doi.org/10.1080/09585190801953491

[18] Quinn, R. and Spreitzer, R.G. (1991) The Psychometrics of the Competing Values Culture Instrument and an Analysis of the Impact of Organizational Culture on Quality of Life. Research in Organizational Change and Development, 5, 115-142.

[19] Ren, F. and Zhang, J. (2015) Job Stressors, Organizational Innovation Climate, and Employees' Innovative Behavior. Creativity Research Journal, 27, 16-23. https://doi.org/10.1080/10400419.2015.992659

[20] Tang, J. (2006) Research on the Influence of Interaction on Trust and Purchasing Behavior in B2C Environment. Fudan University, Shanghai.

[21] Den Hartog, D.N., Van Muijen, J.J. and Koopman, P.L. (1996) Linking Transformational Leadership and Organizational Culture. The Journal of Leadership Studies, 3, 106. https://doi.org/10.1177/107179199600300407

[22] Gefen, D., Karahanna, E. and Straub, D.W. (2003) Trust and Tam in Online Shopping: An Integrated Model. MIS Quarterly, 27, 51-90.

[23] Yin, J. and Straub, D. (2002) Interactivity of Internet-Based Communications: Impacts on E-Business Consumer Decisions. ICIS 2002 Proceedings, Barcelona, 15-18 December 2002, Paper 62.

[24] Farmer, S.M., Tierney, P. and Kung-Mcintyre, K. (2003) Employee Creativity in Taiwan: An Application of Role Identity Theory. Academy of Management Journal, 46, 618-630. https://doi.org/10.2307/30040653

[25] Hayes, A.F. (2013) Introduction to Mediation, Moderation, and Conditional Process Analysis: A Regression-Based Approach. Sage, Newcastle upon Tyne.

[26] Zhao, X., Lynch Jr., J.G. and Chen, Q. (2010) Reconsidering Baron and Kenny: Myths and Truths about Mediation Analysis. Journal of Consumer Research, 37, 197-206. https://doi.org/10.1086/651257

[27] Amabile, T.M. (2004) Leader Behaviors and Work Environment for Creativity: Perceived Leader Support. Leadership Quarterly, 5, 5-32.

https://doi.org/10.1016/j.leaqua.2003.12.003 
[28] Shareholder, B.M. (2007) Influence Capacity and the Variability of Financial Returns to Corporate Social Responsibility. Academy of Management Review, 32, 794-816. https://doi.org/10.5465/AMR.2007.25275520

[29] Zhou, J. (2003) When the Presence of Creative Coworkers Is Related to Creativity: Role of Supervisor Close Monitoring, Developmental Feedback, and Creative Personality. Journal of Applied Psychology, 88, 413-422. https://doi.org/10.1037/0021-9010.88.3.413

[30] Hirst, G., Van Knippenberg, D., Zhou, J., Quintane, E. and Zhu, C. (2015) Heard It through the Grapevine: Indirect Networks and Employee Creativity. Journal of Applied Psychology, 100, 567-574. https://doi.org/10.1037/a0038333

[31] Perry-Smith, J.E. and Shalley, C.E. (2003) The Social Side of Creativity: A Static and Dynamic Social Network Perspective. Academy of Management Review, 28, 89-106. 


\section{Appendix}

\section{The Questionnaire about Team Members' Social Media Interaction Perception, Colleagues' Trust and Employee Creativity}

\section{Dear Sir/Madam:}

Hello! First of all, thank you for taking the time to fill out the questionnaire. This is a questionnaires about team members' social media interaction perception, colleague trust and employee creativity. The purpose of the survey is to examine the intrinsic relationship between the three variables. The survey data is only used for academic research, the answer to the question does not matter right or wrong, the questionnaire is filled with anonymous form, it will never bring you any inconvenience and disadvantage. If it caused any adverse effects on you, I am willing bear all the consequences.

Finally, I sincerely hope that you can truthfully fill in it.

\section{South China University of Technology, Institute of Business Administration}

1. Please fill in the following questions according to your personal situation and play $\sqrt{ }$ in the corresponding box.

2. Team Members' Social Media Interaction Perception.

\begin{tabular}{|c|c|c|c|c|c|c|c|c|}
\hline 1. Gender & & $\square$ Male & $\square$ Female & & & & & \\
\hline 2. Age & & $\square 25$ years old and below & $\square 26-30$ & & -35 & $\square 36-40$ & & $\square 41-50$ \\
\hline 3. Educatio & n level & $\square$ College Graduated and below & $\square$ Bachelor & & aster & $\square$ Doctor & & \\
\hline 4. Years of & entry & $\square$ Less than 2 years & $\square 2-6$ years & & 9 years & $\square$ More th & 9 years & \\
\hline $\begin{array}{l}\text { Serial } \\
\text { number }\end{array}$ & $\begin{array}{l}\text { This s } \\
\text { your } t \\
\text { (micr }\end{array}$ & $\begin{array}{l}\text { e actual experience of interactir } \\
\text { ental colleagues through social } \\
\text { MSN, email, forums, etc.) }\end{array}$ & & $\begin{array}{l}\text { Strongly } \\
\text { Disagree }\end{array}$ & Disagree & $\begin{array}{c}\text { No } \\
\text { Comment }\end{array}$ & Agree & $\begin{array}{l}\text { Totally } \\
\text { Agree }\end{array}$ \\
\hline 1 & $\begin{array}{l}\text { Throu } \\
\text { my co }\end{array}$ & nteraction, the information I can & rom & & & & & \\
\hline 2 & $\begin{array}{l}\text { Throu } \\
\text { collea }\end{array}$ & $\begin{array}{l}\text { nteraction, the information obtair } \\
\text { efficiency of my access to inform }\end{array}$ & $\begin{array}{l}\text { from } \\
\text { n. }\end{array}$ & & & & & \\
\hline 3 & $\begin{array}{l}\text { Throu } \\
\text { I want }\end{array}$ & $\begin{array}{l}\text { nteraction, I can get the informat } \\
\text { ues. }\end{array}$ & & & & & & \\
\hline 4 & $\begin{array}{l}\text { Throu } \\
\text { colleas }\end{array}$ & $\begin{array}{l}\text { nteraction, information obtained } \\
\text { ise work. }\end{array}$ & & & & & & \\
\hline 5 & $\begin{array}{l}\text { In the } \\
\text { my qu }\end{array}$ & raction process, I can immediatel & swer & & & & & \\
\hline 6 & $\begin{array}{l}\text { In the } \\
\text { statem }\end{array}$ & $\begin{array}{l}\text { raction process, colleagues will us } \\
\text { st "yes" or "no" to reply to my qu }\end{array}$ & $\begin{array}{l}\text { e complete } \\
\text { n. }\end{array}$ & & & & & \\
\hline 7 & $\begin{array}{l}\text { In the } \\
\text { provid }\end{array}$ & $\begin{array}{l}\text { media interaction, my colleagues } \\
\text { ation for my inquiry. }\end{array}$ & & & & & & \\
\hline 8 & $\begin{array}{l}\text { In the } \\
\text { to my }\end{array}$ & media interaction, colleagues resp & led closely & & & & & \\
\hline 9 & $\begin{array}{l}\text { In the } \\
\text { comm }\end{array}$ & raction process, my colleagues ar & ppy to & & & & & \\
\hline 10 & $\begin{array}{l}\text { Durin } \\
\text { listen }\end{array}$ & interaction, my colleague was ha & & & & & & \\
\hline
\end{tabular}




\section{Continued}

11 In the process of social media interaction, my colleagues can understand my problems very well.

12

During the social media interaction, I felt that I could understand the replies from my colleagues.

In the process of social media interaction, we can get a lot of good advice and suggestions from my colleagues.

14 In the process of social media interaction, we can share knowledge, experience and information with each other. $\mathrm{n}$ the social media interaction process, if a lack of understanding of something, always get help from colleagues there.

16

In the process of social media interaction, we encourage our own experiences, opinions and suggestions.

\section{Colleagues' Trust}

\begin{tabular}{|c|c|c|c|c|c|c|}
\hline $\begin{array}{c}\text { Serial } \\
\text { number }\end{array}$ & This section is about your trust in your colleagues & $\begin{array}{l}\text { Strongly } \\
\text { Disagree }\end{array}$ & Disagree & $\begin{array}{c}\text { No } \\
\text { Comment }\end{array}$ & Agree & $\begin{array}{l}\text { Totally } \\
\text { Agree }\end{array}$ \\
\hline 17 & $\begin{array}{l}\text { I and my colleagues are a shared relationship, we are free to share a } \\
\text { variety of ideas, feelings and expectations of the heart. }\end{array}$ & & & & & \\
\hline 18 & $\begin{array}{l}\text { I can talk to my colleagues with no hesitation about the difficulties I } \\
\text { encountered in my work and I know he/she is willing to listen. }\end{array}$ & & & & & \\
\hline 19 & $\begin{array}{l}\text { If one of my colleagues and my colleagues were transferred and could } \\
\text { not work together, I would have a sense of loss. }\end{array}$ & & & & & \\
\hline 20 & $\begin{array}{l}\text { If I talk to my colleagues about my question, I know that he/she will } \\
\text { care about me and give me constructive advice. }\end{array}$ & & & & & \\
\hline 21 & $\begin{array}{l}\text { In my working relationship with my colleagues, we have put a lot of } \\
\text { emotion. }\end{array}$ & & & & & \\
\hline 22 & My colleague's attitude towards work is professional and devoted. & & & & & \\
\hline 23 & $\begin{array}{l}\text { According to my contact with my colleagues, I have no reason to doubt } \\
\text { his/her ability and attitude. }\end{array}$ & & & & & \\
\hline 24 & $\begin{array}{l}\text { I can believe that my colleagues will not carelessly at work, so that my } \\
\text { job becomes more difficult to complete. }\end{array}$ & & & & & \\
\hline 25 & $\begin{array}{l}\text { I believe that even if there is no personal interaction, most people will } \\
\text { believe and respect my colleagues. }\end{array}$ & & & & & \\
\hline 26 & My superiors also believe that my colleagues are trustworthy people. & & & & & \\
\hline
\end{tabular}

\section{Supporting Organizational Culture}

\begin{tabular}{|c|c|c|c|c|c|c|}
\hline $\begin{array}{c}\text { Serial } \\
\text { number }\end{array}$ & $\begin{array}{l}\text { This section covers your perception of your company's corporate } \\
\text { culture }\end{array}$ & $\begin{array}{l}\text { Strongly } \\
\text { Disagree }\end{array}$ & Disagree & $\begin{array}{c}\text { No } \\
\text { Comment }\end{array}$ & Agree & $\begin{array}{l}\text { Totally } \\
\text { Agree }\end{array}$ \\
\hline 27 & The Company treats employees equally. & & & & & \\
\hline 28 & The company's work can give people a sense of security. & & & & & \\
\hline 29 & The Company gives employees considerable autonomy and freedom. & & & & & \\
\hline 30 & Our employees work together with each other to work together. & & & & & \\
\hline 31 & The company has a complete rules and regulations for staff to follow. & & & & & \\
\hline 32 & Our employees trust each other. & & & & & \\
\hline
\end{tabular}


Z. Q. Huang et al.

5. Employee Creativity

\begin{tabular}{|c|c|c|c|c|c|c|}
\hline $\begin{array}{c}\text { Serial } \\
\text { number }\end{array}$ & This section covers your true assessment of your creativity & $\begin{array}{l}\text { Strongly } \\
\text { Disagree }\end{array}$ & Disagree & $\begin{array}{c}\text { No } \\
\text { Comment }\end{array}$ & Agree & $\begin{array}{c}\text { Totally } \\
\text { Agree }\end{array}$ \\
\hline 33 & Tries new ideas or methods first. & & & & & \\
\hline 34 & Seeks new ideas and ways to solve problems. & & & & & \\
\hline 35 & Generates ground-breaking ideas related to the field. & & & & & \\
\hline 36 & Is a good role model for creativity. & & & & & \\
\hline
\end{tabular}

